\title{
Examining how International Experiences Promote Global Competency among Engineering Graduate Students
}

\author{
Lauren B. Denney, Matilde Sanchez-Pena, and Joyce B. Main
} Department of Engineering Education, Purdue University

\begin{abstract}
Employers across the globe are seeking engineers that possess more "soft skills": leadership, communication, and teamwork skills. In addition to these characteristics as well as the traditional engineering problem solving skills, engineers are required to have attributes of global competency which would help them thrive in the global workforce. A plethora of information and studies exist on undergraduate students and their global competency development. Despite these efforts, there is little information on engineering doctoral students and methods for increasing their levels of global competency. Doctoral students are at the forefront of scientific and technological innovation and discoveries, so it is critical that they are trained to work effectively in diverse environments. This study comparatively examines the intercultural experiences of a) engineering doctoral students from the U.S. who traveled abroad, and $b$ ) international engineering doctoral students who traveled to the U.S. Findings show that both groups of students prepared themselves to go abroad in multiple ways, and that some domestic students abroad reported negative experiences due to a mismatch between pre-travel expectations and actual experiences abroad. International students experienced greater adjustment outcomes when they had greater levels of support, and these students also frequently mentioned cross-cultural differences rather than similarities. Findings of our study can help U.S. and international academic institutions identify strategies to increase graduate students' global competency levels.
\end{abstract}

\section{KEYWORDS}

Doctoral students, global competency, study abroad, international experience, engineering 